\section{Microbiological surveillance of hospital environment in a Medical College Hospital in Kathmandu, Nepal}

\author{
Pradhan SB, Shrestha CD*
}

Department of Pathology, Kathmandu Medical College Teaching Hospital, Kathmandu, Nepal

*Correspondence to: Dr. Chandrika Devi Shrestha, Department of Pathology, Kathmandu medical College teaching Hospital, Kathmandu, Nepal, email: cdshrestha@googlemail.com, Tel. No.: (+977)-9851098656

\begin{abstract}
INTRODUCTION: Hospital acquired infections (HAI) are serious problems in the patient care and management despite antimicrobial therapy and advances in supportive care in developing countries. Regular cleaning following institutionalized guidelines of infection control policies can minimize the possibility of contamination and prevent the HAI so that the morbidity and mortality related to HAI will be reduced.
\end{abstract}

MATERIALS AND METHODS: Descriptive analysis of the culture growth of the samples from different sites of the Kathmandu Medical College Teaching Hospital (KMCTH) environment from $4^{\text {th }}$ March, 2011 to $4^{\text {th }}$ April, 2012 was done. The swabs were taken before and after fumigation and disinfection and number of colonies grown were used to monitor the effectiveness of the intervention. The cultures and Gram staining were performed as per standard microbiological procedures in Clinical Microbiology Laboratory, Department of Pathology, Kathmandu Medical College Teaching Hospital.

RESULTS: Almost all the floors of the hospital wards swabbed were contaminated with the bacteria. The bacteria that grew from the environment ranged from 50 to 140 colonies in Medical Intensive Care Unit and Special High Care Unit respectively. Common contaminants were Staphylococci spp., Gram negative diplococcic, and Gram positive. The Staphylococci spp. contaminated air in most of the wards. The number of colonies after fumigation and disinfection were drastically decreased from no growth to 15 colonies.

CONCLUSIONS: Environment was contaminated with microorganisms. Even after regular cleaning and disinfection, bacterial growth was seen. To prevent any contamination prior HAI develops, hospital needs to develop programmes for the implementation of good infection control practices.

KEY WORDS: Hospital acquired infection (HAI), Environment contamination, Fumigation

Article submitted 08 November 2012. Reviewed 12 December 2012. Author correction 25 December 2012. Final version accepted 09 January 2013. 


\section{INTRODUCTION}

Hospital Acquired Infections (HAIs) or nosocomial infections are those infections that were neither present nor incubating at the time the patient was admitted to the health care facility. ${ }^{1}$ The patients with infectious diseases are frequently admitted to hospital. Some of these patients are able to spread their organisms to other patients and they provide one source of infection in the patients admitted in the hospital for other causes. ${ }^{1}$

Bacteria and viruses are natural inhabitants of the environment, both in the community and in the hospital. ${ }^{1}$ Air borne droplets nuclei generated during coughing or sneezing are a potential source of transmission of infection either by direct inhalation or indirectly through contaminated medical devices. ${ }^{1}$ Droplets generated from the infected respiratory tract can remain airborne for long period of time and transmit infection like Tuberculosis, respiratory viral illness etc. ${ }^{1}$

The environment in the hospital plays an important role in the occurrence of hospital acquired infection. $2,3,4,5$ The transmission of microorganisms from the environment surfaces to the patients is mainly through the hand contact with the surfaces. Although hand cleaning is important to minimize the transmission, cleaning and disinfecting environment surfaces in a proper way is very important to keep the hospital free of microbes so that the possibility of contamination can be reduced and the incidence of hospital acquired infections can be prevented. 6

Hospital acquired infections are considered as major causes of mortality, emotional stress and enhanced morbidity in hospitalized patients. 7,8 These also account for significant economic loss and additional burden on health care institutions.

The attempt was made to surveillance the microbial contamination of the hospital environment and to look for the effectiveness of regular cleaning and disinfection in the different sites of the hospital and instruments so that appropriate measures can be taken to prevent HAI.

\section{MATERIALS AND METHODS}

Descriptive analysis of the culture growth of the samples from different sites and instruments of the hospital from $4^{\text {th }}$ March, 2011 to $4^{\text {th }}$ April, 2012 was done at Clinical Microbiology Laboratory, Department of Pathology, KMCTH.
Wet swab soaked with Nutrient broth was rubbed over one square inch area from at least 10 strategic sites as planned to collect the sample before and after the fumigation and disinfection. The samples were obtained from Intensive care unit (ICU), Coronary care unit (CCU), Medical intensive care unit (MICU), Neonatal intensive care unit (NICU), Surgical high care unit (SHCU), Operation theatre (OT), Post operative ward, Staff duty rooms, Wards, Cabins, Ventilators, Suction jars, Water taps, etc. These swabs were inoculated into Blood agar (BA) \& Chocolate agar (CA) and incubated over night at $37^{\circ} \mathrm{C}$. For the study of air, Blood agar (BA) \& Chocolate agar (CA) were exposed for 30 minutes using a plate exposure technique and incubated over night at $37^{\circ} \mathrm{C}$.

The plates were read next day for any growth. Numbers of colonies were counted by marking the segments made by vertical and horizontal lines crossing each other at the centre. Gram stain was done for different morphology of colonies following Standard methology. ${ }^{9}$

The standard Guidelines ${ }^{10}$ to evaluate the efficacy of cleaning and disinfection were used as follows; the presence of 0-25 bacteria/cubic foot indicates that floor cleaning procedures are good, the presence of 26-50 bacteria/cubic feet indicates that floor cleaning procedures are just satisfactory and presence of more than 50 bacteria/ cubic foot indicates that floor-cleaning procedures are unsatisfactory. Ethical clearance was taken from ethical review borad of KMCTH.

\section{RESULTS}

Most of the floors of the hospital were contaminated with the bacteria. The number of colonies of the bacteria ranged from 50 to 140 colonies in MICU and SHCU respectively. Staphylococci spp., Gram negative diplococcic, Gram positive bacilli most frequently contaminated the innate articles. Yeast contamination was less. The air was contaminated with Staphylococci spp. in most of the wards. The number of growth of colonies after fumigation and disinfection were drastically decreased from no growth to 15 colonies.

\section{DISCUSSION}

Hospital-acquired infections (HAIs) (also called "nosocomial infections" or "health-care-associated infections") are infections that a patient acquires while in hospital being treated for some other condition. ${ }^{11}$ For the health care system, such 


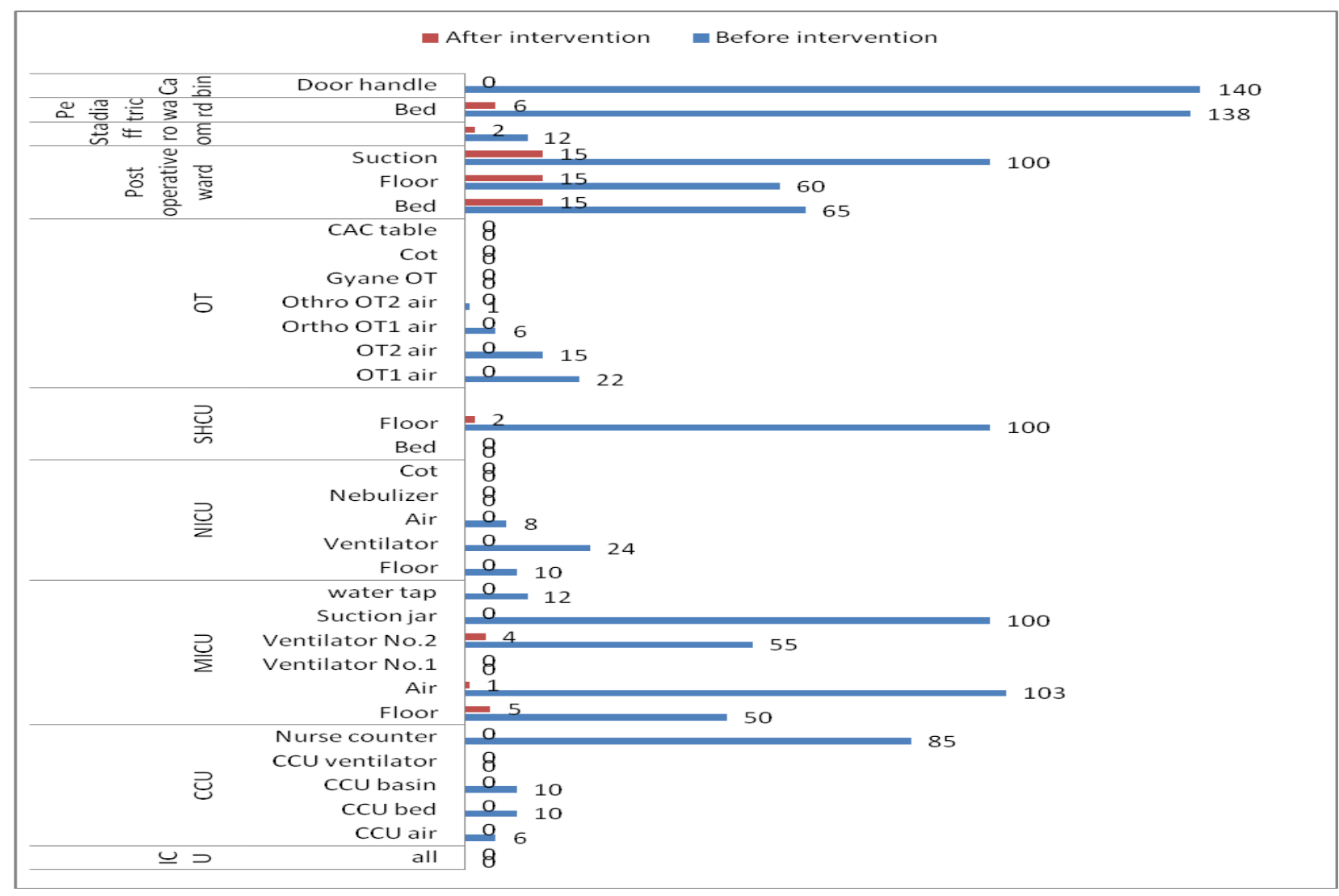

Figure. Number of bacterial colonies grown before and after fumigation and disinfection

infection increase treatment cost and result in longer wait times for a hospital bed for other patients.

In a study done in Canadian hospital in the year 2003, 220,000 cases are due to HAI, resulting 8000 death annually. Recently Canadian Institute of Health information noted that one in 10 adults and one in 12 children will contract an infection while in a Canadian hospital. ${ }^{11}$ In US, the Centers for Disease Control and Prevention estimate that each year, there are 1.7 million HAIs in American hospitals and 99,000 deaths linked to them. ${ }^{11}$

In a study conducted by WHO, the highest frequencies of HAI (11.8\%) were reported from hospital in the Eastern Mediterranean region followed by South East Asia (10\%). ${ }^{1}$ It has also been estimated that these infections cost more than US\$ 40 million every year in Thailand alone. ${ }^{1}$

Such high incidences of HAI in highly developed countries like US, Canada, make us to think about HAI in a developing country like Nepal. Study to look for the incidence of HAI has not been done in Nepal so far however efforts can be made to keep the hospital environment free of microbes to prevent contamination.

Regular cleaning and disinfection is being carried out in Kathmandu Medical College Teaching Hospital. In this study, even after regular cleaning and disinfection, significant growth were seen from most of the sites of the hospital and instruments. The good point is that the samples taken immediately after fumigation and disinfection were found to have less growth. At least, if these cleaning methods are continued and are done very frequently, we can minimize the possibility of contamination and prevent the HAI so that the morbidity and mortality related to HAI will be reduced.

Besides this, every hospital in Nepal needs to strengthened and develop a programme for the implementation of good infection control practices and to ensure the well being of both patients and staffs by preventing and controlling the possibility of contamination. The objectives of this programme will be monitoring of hospital associated infections, monitoring of staff to prevent staff to patient and patient to staff spread of infections, training of staffs 
in prevention and control of HAI, isolation procedures and infection control measures etc.

Infection control committee consisting of Medical Microbiologist, Nursing in charge, Administrative officer and Central sterile supplies department (CSSD). This committee will recommend for the proper design of ward and OT, air quality, proper handling of medical waste and laundry, appropriate hand washing facilities, safe water supply, adequate isolation facilities, adequate ventilation, traffic flow to minimize exposure to high risk patient, regular routine wet mopping and cleaning with disinfectant solution in high risk areas and disinfectant soaked door mats at every entrance.

Disinfectant sprays and proper ventilation may help to control airborne infective particles. An inspection should be made daily of all individuals reporting for duty in operating rooms, surgical wards, obstetric services, pediatric ward, central supply and food handling areas. A person suffering from an active infection and also the carriers are dangerous. Therefore, individuals with evidence of active infection should be identified and removed from critical areas at the earliest.

An attempt should be made to achieve and maintain an average count of 10-15 bacteria / cubic foot of air in the hospital. When there are less than 5 bacteria/cubic feet, there is a very minimal risk of infection. When there are more than 35 bacteria/ cubic foot of air, there is a heightened risk of infection from air. 10

\section{CONCLUSION}

Even after regular cleaning and disinfection, significant bacterial contamination was noted. Continuous microbiological surveillance of hospital environment with the institutionalized infection control and prevention practices will prevent HAI.

\section{ACKNOWLEDGEMENT}

We would like to thank Prof. Dr. Toran KC, Director, Kathmandu Medical College Teaching Hospital and Dr. Abhinav Vaidya for his critical suggestions and cooperation during the manuscript preparation.

CONFLICT OF INTEREST: None to declare.

FINANCIAL INTEREST: None to declare.

\section{REFERENCES}

1. World Health Organization. General Guidelines on Prevention and control of Hospital Associated Infections. New Delhi; WHO Regional Office for South-East Asia;2002. 2. Ekrami AR, Kayedani A, Jahangir M, Kalantar E, Jalali M. Isolation of common aerobic bacterial pathogens from the environment of seven hospitals, Ahvaz, Iran. Jundishapur J Microbiol. 2011;4:75-82.

3. Bruetti L, Santoro E, Decaro F, et al. Surveillance of nosocomial infections: a preliminary study on hand hygiene compliance of healthcare workers. J Prev Med Hyg 2006;47:64-68.

4. Manning ML, Archibald LK, Bell LM, et al. Serratia marcescens transmission in a pediatric intensive care unit: a multifactorial occurrence. Am J Infect Control 2001;29:115-119.

5. Ciragil P, Gul M, Aral M. Bacterial contamination of computers and telephones in a university hospital in Turkey. J Hosp Infect 2006;62:247-248.

6. Kampf G, Kramer A. Epidemiologic background of hand hygiene and evaluation of the most important agents for scrubs and rubs. Clin Microbial Rev. 2004; 17:863-93

7. Jarvis WR. Selected aspects of the socioeconomic impact of nosocomial infections: morbidity, mortality, cost, and prevention .Infect Control Hosp Epidemiol 1996;17:552-557.

8. Stosor V, Peterson LR, Postelnick M, et al. Enterococcus faecium bacteremia: does vancomycin resistance make a difference? Arch Intern Med 1998;158:522-7.

9. Monica Cheelsbrough. Medical Laboratory Manual for Tropical Countries. England: 2nd ed. (vol. II)., The Thehford press Ltd.; 1984.

10. Ananathanarayan R, Paniker CKJ. Textbook of Microbiology, $8^{\text {th }}$ Ed. India: Universities Press Pvt. Ltd.; 2009.

11. Prevention and Control of Hospital-acquired Infections. Special report in Ontario. 2008

\section{Citing this article}

Pradhan SB, Shrestha CD. Microbiological surveillance of hospital environment in a Medical College Hospital in Kathmandu, Nepal. Int J Infect Microbiol 2012;1(2);76-79. 